\title{
The ionic interaction of Klebsiella pneumoniae K2 capsule and core lipopolysaccharide
}

\begin{abstract}
Correspondence
Juan M. Tomás

jtomas@ub.edu
\end{abstract}

Received 20 October 2005

Revised 5 February 2006

Accepted 6 February 2006

\author{
Sandra Fresno, ${ }^{1}$ Natalia Jiménez, ${ }^{1}$ Luis Izquierdo, ${ }^{1}$ Susana Merino, ${ }^{1}$ \\ Maria Michela Corsaro, ${ }^{3}$ Cristina De Castro, ${ }^{3}$ Michelangelo Parrilli, ${ }^{3}$ \\ Teresa Naldi, ${ }^{3}$ Miguel Regué ${ }^{2}$ and Juan M. Tomás ${ }^{1}$
'Departamento de Microbiología, Facultad de Biología, Universidad de Barcelona, Diagonal 645, 08071 Barcelona, Spain
${ }^{2}$ Departamento de Microbiología y Parasitología Sanitarias, Facultad de Farmacia, Universidad de Barcelona, Av. Joan XXIII s/n, 08028 Barcelona, Spain
${ }^{3}$ Dipartimento di Chimica e Biochimica, Università Federico II di Napoli, Complesso Universitario Monte S. Angelo, Via Cintia 4, 80126 Napoli, Italy

\begin{abstract}
The complete structures of LPS core types 1 and 2 from Klebsiella pneumoniae have been described by other authors. They are characterized by a lack of phosphoryl residues, but they contain galacturonic acid ( $\mathrm{GalA}$ ) residues, which contribute to the necessary negative charges. The presence of a capsule was determined in core-LPS non-polar mutants from strains 52145 (O1 : K2), DL1 (O1:K1) and C3 (O8: K66). O-antigen ligase (waaL) mutants produced a capsule. Core mutants containing the GalA residues were capsulated, while those lacking the residues were non capsulated. Since the proteins involved in the transfer of GalA (WabG) and glucosamine residues $(\mathrm{WabH})$ are known, the chemical basis of the capsular-K2-cell-surface association was

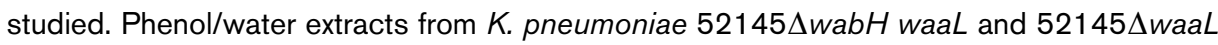
mutants, but not those from from $K$. pneumoniae $52145 \Delta$ wabG waaL mutant, contained both LPS and capsular polysaccharide, even after hydrophobic chromatography. The two polysaccharides were dissociated by gel-filtration chromatography, eluting with detergent and metal-ion chelators. From these results, it is concluded that the K2 capsular polysaccharide is associated by an ionic interaction to the LPS through the negative charge provided by the carboxyl groups of the GalA residues.
\end{abstract}

\section{INTRODUCTION}

Klebsiella spp. strains, particularly Klebsiella pneumoniae, are important causes of nosocomial infections (Emori \& Gaynes, 1993). K. pneumoniae infections can occur in almost all body sites, but the highest incidence is in the urinary and the respiratory tracts. The main populations at risk are neonates, immunocompromised hosts, and patients predisposed by surgery, diabetes, malignancy, etc. (Emori \& Gaynes, 1993; Hansen et al., 1999; Hervás et al., 1993). The existence of multiple antibiotic-resistant $K$. pneumoniae strains is well known, and they have complicated therapy. Mortality rates of up to $50 \%$ have been found in respiratory

Abbreviations: DOC, deoxycholate; EM, electron microscopy; GalA, galacturonic acid; Glc, D-glucopyranose; GlcN, D-glucosamine; Hep, Lglycero-D-manno-heptopyranose; Kdo, 3-deoxy-D-manno-oct-2-ulosonic acid; K-PS, capsular polysaccharide; MALDI-TOF, matrix-assisted laser desorption ionization time-of-flight; $\mathrm{NaOAc}$, sodium acetate; OM, outer membrane; OMP, outer-membrane protein; O-PS, O-antigen polysaccharide; OS, oligosaccharide(s); PCP, phenol/chloroform/light petroleum ether; PW, phenol/water. tract infections. As an alternative to antibiotic treatment, prevention and/or treatment of K. pneumoniae infections by immunotherapy have received increased attention in recent years.

K. pneumoniae strains typically express smooth LPS, LPS with O-antigen polysaccharide (O-PS), and antigenic capsular polysaccharide (K-PS) on their surface; both O-PS and K-PS contribute to the pathogenesis of the species. The $K$. pneumoniae K-PS plays a critical role in the ability of the organism to resist complement-mediated opsonophagocytic killing (Williams \& Tomás, 1990). Furthermore, an extracellular complex containing LPS and capsule has been suggested to be involved in lung damage (Straus et al., 1985). More than 90 different capsular types (K-antigens) have been described in Klebsiella, but only the gene clusters involved in $\mathrm{K} 2\left(w c a_{\mathrm{K} 2}\right)$ and $\mathrm{K} 57\left(w c a_{\mathrm{K} 57}\right)$ antigens have been described (Arakawa et al., 1995). The two known wca gene clusters contain genes involved in K-PS residue biosynthesis, linkage, polymerization and export. In addition, the production of the $\mathrm{K} 2$ requires a $w c a_{\mathrm{K} 2}$ plasmid-borne capsular 
gene transcriptional activator (Arakawa et al., 1995; Lai et al., 2003).

In a few Gram-negative K-PS-containing bacteria, the basis of K-antigen attachment to the cell surface involves an interaction with a lipid moiety, either the LPS domain lipid A core (Jann et al., 1992), or a glycerolipid (Gotschlich et al., 1981; Kuo et al., 1985). However, despite its importance as a pathogenic factor, little is known about the linkage of the K. pneumoniae K-PS to the cell surface. Knowledge of the chemical structures of the O1-antigen, core LPS, lipid A (Vinogradov et al., 2002; Süsskind et al.1995; Vinogradov \& Perry, 2001, Helander et al., 1996), and K2 (Corsaro et al.,
2005) antigens from K. pneumoniae, as well as the genes involved in their biosynthesis (Arakawa et al., 1995; Kelly et al., 1993; Regué et al., 2001, 2005a), have enabled us to study the basis of the K2-capsule-cell-surface interaction.

\section{METHODS}

Bacterial strains, bacteriophages, plasmids and growth conditions. Klebsiella pneumoniae strains and plasmids used in this study are shown in Table 1. Bacterial strains were grown in LB broth and on LB agar (Miller, 1972). LB media were supplemented with kanamycin $\left(50 \mu \mathrm{g} \mathrm{ml}^{-1}\right)$, ampicillin $\left(100 \mu \mathrm{g} \mathrm{m}^{-1}\right)$, chloramphenicol $\left(20 \mu \mathrm{g} \mathrm{ml}^{-1}\right)$ and tetracycline $\left(25 \mu \mathrm{g} \mathrm{ml}^{-1}\right)$ when needed.

Table 1. Bacterial strains and plasmids used

\begin{tabular}{|c|c|c|}
\hline Strain or plasmid & Relevant characteristics & Reference or source \\
\hline \multicolumn{3}{|l|}{ K. pneumoniae } \\
\hline DL1 & Serovar $\mathrm{O} 1: \mathrm{K} 1$ & Tomás et al. (1988) \\
\hline $\mathrm{DL} 1 \Delta w a a L$ & Non-polar waaL mutant & This study \\
\hline $\mathrm{DL} 1 \Delta w a b G$ & Non-polar wabG mutant & This study \\
\hline $\mathrm{DL} 1 \Delta w a b G w a a L$ & Double non-polar wabG waaL mutant & This study \\
\hline $\mathrm{DL} 1 \Delta w a b H$ & Non-polar wabH mutant & This study \\
\hline $\mathrm{DL} 1 \Delta w a b H w a a L$ & Double non-polar wabH waaL mutant & This study \\
\hline 52145 & Serovar $\mathrm{O} 1: \mathrm{K} 2$ & Nassif et al. (1989) \\
\hline $52145 \Delta w a a F$ & Non-polar waaF mutant & Izquierdo et al. (2003) \\
\hline $52145 \Delta w a a C$ & Non-polar waaC mutant & Izquierdo et al. (2003) \\
\hline $52145 \Delta w a b K$ & Non-polar wabK mutant & Regué et al. (2005b) \\
\hline $52145 \Delta$ waaL & Non-polar waaL mutant & Izquierdo et al. (2003) \\
\hline $52145 \Delta w a b M$ & Non-polar wabM mutant & Regué et al. (2005b) \\
\hline $52145 \Delta w a b G$ & Non-polar wabG mutant & Izquierdo et al. (2003) \\
\hline $52145 \Delta w a b G w a a L$ & Double non-polar wabG waaL mutant & Regué et al. (2005a) \\
\hline $52145 \Delta w a b H$ & Non-polar wabH mutant & Regué et al. (2005a) \\
\hline $52145 \Delta w a b H$ waaL & Double non-polar wabH waaL mutant & Regué et al. (2005a) \\
\hline $52145 \Delta w a a E(\mathrm{NC} 16)$ & Non-polar waaE mutant & Regué et al. (2001) \\
\hline $\mathrm{C} 3$ & Serovar O8: K66 & Ørskov \& Ørskov (1984) \\
\hline $\mathrm{C} 3 \Delta w a a F$ & Non-polar waaF mutant & Izquierdo et al. (2003) \\
\hline $\mathrm{C} 3 \Delta w a a C$ & Non-polar waaC mutant & Izquierdo et al. (2003) \\
\hline $\mathrm{C} 3 \Delta w a b I$ & Non-polar wabI mutant & This study \\
\hline $\mathrm{C} 3 \Delta w a a L(\mathrm{NC} 20)$ & Non-polar waaL mutant & Regué et al. (2001) \\
\hline $\mathrm{C} 3 \Delta w a b J$ & Non-polar wabJ mutant & This study \\
\hline $\mathrm{C} 3 \Delta w a b G$ & Non-polar wabG mutant & Izquierdo et al. (2003) \\
\hline $\mathrm{C} 3 \Delta w a b G w a a L$ & Double non-polar wabG waaL mutant & Regué et al. (2005a) \\
\hline $\mathrm{C} 3 \Delta w a b H$ & Non-polar wabH mutant & Regué et al. (2005a) \\
\hline $\mathrm{C} 3 \Delta w a b H$ waaL & Double non-polar wabH waaL mutant & Regué et al. (2005a) \\
\hline $\mathrm{C} 3 \Delta w a a E$ & Non-polar waaE mutant & Izquierdo et al. (2003) \\
\hline \multicolumn{3}{|l|}{ Plasmid } \\
\hline pKO3 & $\begin{array}{l}\mathrm{Cm}^{\mathrm{r}} \text { temperature-sensitive replication } \\
\text { sacB-containing suicide plasmid }\end{array}$ & Link et al. (1997) \\
\hline $\mathrm{pKO} 3 \Delta w a a C$ & Contains an internal non-polar waaC deletion & Izquierdo et al. (2003) \\
\hline $\mathrm{pKO} 3 \Delta w a a F$ & waaF deletion & Izquierdo et al. (2003) \\
\hline $\mathrm{pKO} 3 \Delta w a b I_{\mathrm{C} 3}$ & Contains an internal non-polar wabI deletion & Regué et al. (2005a) \\
\hline $\mathrm{pKO} 3 \Delta w a a L_{-D L 1}$ & Contains an internal non-polar waaL deletion & Regué et al. (2001) \\
\hline $\mathrm{pKO} 3 \Delta w a b J_{\mathrm{C} 3-}$ & Contains an internal non-polar wabJ deletion & Regué et al. (2005a) \\
\hline $\mathrm{pKO} 3 \Delta w a b G$ & Contains an internal non-polar $w a b G$ deletion & Izquierdo et al. (2003) \\
\hline $\mathrm{pKO} 3 \Delta w a b H$ & Contains an internal non-polar $w a b H$ deletion & Regué et al. (2005a) \\
\hline
\end{tabular}


Bacteriophages FC3-9, $\phi 1$ and $\phi 2$, specific for capsular serovars K66, $\mathrm{K} 1$ and K2, respectively, have been described previously (Camprubí et al., 1992; Regué et al., 2004).

ELISAs. Whole cells, culture supernatants, cell-surface extracts or chromatographic fractions were studied with anti-K1-, -K2- or -K66-specific antiserum, as previously described for whole cells (Camprubí et al., 1992; Regué et al., 2004).

General DNA methods. General DNA manipulations were done essentially as described (Sambrook et al., 1989). DNA restriction endonucleases, T4 DNA ligase, Escherichia coli DNA polymerase (Klenow fragment), and alkaline phosphatase were used as recommended by the suppliers.

Mutant construction. K. pneumoniae individual genes were mutated by creating in vitro in-frame deletions of each gene. Each mutated gene was transferred to the chromosome by homologous recombination using the temperature-sensitive suicide plasmid $\mathrm{pKO} 3$, containing the counterselectable marker sacB (Link et al., 1997). Mutations were made in waaL and wabI $J G$ and $H$. The plasmids containing the engineered in-frame deletions derived from DL1 $\left(\mathrm{pKO} 3 \Delta w a a L_{\mathrm{DL} 1}\right)$, and $\mathrm{C} 3\left(\mathrm{pKO} 3 \Delta w a b I_{\mathrm{C} 3}\right.$ and $\left.\mathrm{pKO} 3 \Delta w a b J_{\mathrm{C} 3}\right)$ sequences were transformed into $K$. pneumoniae $\mathrm{C} 3$ and DL1, respectively, by electroporation. Mutants were selected based on growth on LB agar containing $10 \%$ sucrose, and loss of the chloramphenicol resistance marker of vector $\mathrm{pKO}$. The mutations were confirmed by sequencing of the whole constructs in amplified PCR products. The DL1 1 waaL mutant was constructed by asymmetric PCR amplifications using DL1 chromosomal DNA and primers LA DL1 (5'-CGCGCGGCCGCAGCGCGCTGAAAAACAGTAT- $\left.3^{\prime}\right)$, LB $_{\text {DL1 }}$ (5' $5^{\prime}$-CCATCCACTAAACTTAAACAACCCTGTCTGGCGAAGTTA-3'), LC DL1 $^{\prime}\left(5^{\prime}-\right.$ TGTTTAAGTTTA GTGGATGGGGCGGAAAAACGCTAACAAA-3') and LD DL1 $\left(5^{\prime}\right.$-GAGCGGCCGCCTGCTATTGCGTCTGGATGA-3'). The primers include NotI sites (single underlined). DNA fragments of $803\left(\mathrm{LA}_{\mathrm{DL} 1}-\mathrm{LB}_{\mathrm{DL} 1}\right)$ and $1037\left(\mathrm{LC}_{\mathrm{DL} 1}-\mathrm{LD}_{\mathrm{DL} 1}\right)$ bp were obtained. DNA fragment $\mathrm{LA}_{\mathrm{DL} 1}-\mathrm{LB}_{\mathrm{DL} 1}$ included nt 3430 , inside wabI, to $\mathrm{nt}$ 4200 , corresponding to the third base of the eighth codon of waaL. DNA fragment $\mathrm{LC}_{\mathrm{DL} 1}-\mathrm{LD}_{\mathrm{DL} 1}$ included the last four codons of waaL (nt 5315) to nt 6320 , inside wabJ. DNA fragments $\mathrm{LA}_{\mathrm{C} 3}-\mathrm{LB}_{\mathrm{C} 3}$ and $\mathrm{LC}_{\mathrm{DL} 1}-\mathrm{LD}_{\mathrm{DL} 1}$ were annealed at their overlapping region (doubleunderlined in primers $\mathrm{LB}_{\mathrm{DL} 1}$ and $\mathrm{LC}_{\mathrm{DL} 1}$ ), and amplified by $\mathrm{PCR}$ as a single fragment, using primers $\mathrm{LA}_{\mathrm{DL} 1}$ and $\mathrm{LD}_{\mathrm{DL} 1}$. The fusion product was purified, NotI digested, ligated into NotI-digested and phosphatase-treated $\mathrm{pKO} 3$ vector, electroporated into E. coli $\mathrm{DH} 5 \alpha$, and plated on chloramphenicol $\mathrm{LB}$ agar at $30^{\circ} \mathrm{C}$ to obtain plasmid pKO3 3 waa $_{\mathrm{DL1}}$. Similarly, primers sets I [IA $\mathrm{I}_{\mathrm{C} 3}\left(5^{\prime}\right.$-CGCGCGGCCGCAGCCTGTTTTACAACCGCC-3'), IB ${ }_{\mathrm{C} 3}$ (5'-CCCATCCACTAAACTTAAACACAGGGATCCCATCAGAGC-3'), IC $\mathrm{C}_{\mathrm{C} 3}\left(5^{\prime}\right.$-TGTTTAAGTTTAGTGGATGGGATCTTCGAAAAGGTTGCGTTT- $\left.3^{\prime}\right)$ and ID $_{\mathrm{C} 3}\left(5^{\prime}-\right.$ CGCGCGGCCGCGTATGGTGCCAGATGCTCAG-3')] and $\mathrm{J}$ [JA ${ }_{\mathrm{C} 3}$ (5' -CGCGCGGCCGCACCATACGCTGGTTCTCACC-3'), JB ${ }_{\mathrm{C} 3}\left(5^{\prime}\right.$ TGTTTAAGTTTAGTGGATGGGGCCGGCTTATTTCTGTATCG- ${ }^{\prime}{ }^{\prime}$ ), JC ${ }_{\mathrm{C} 3}\left(5^{\prime}\right.$-CCCATCCACTAAACTTAAACAATGTGGCCCGTGATTAAAGAG-3') and JD ${ }_{\mathrm{C} 3}\left(5^{\prime}\right.$-CGCGCGGCCGCCTTATTGAATACAGCGACG-3')] were used to construct pKO3 $3 w a b I_{\mathrm{C} 3}$ and $\mathrm{pKO} 3 \Delta w a b J_{\mathrm{C} 3}$, respectively. Plasmid pKO3 $\Delta w a b I_{\mathrm{C} 3}$ included nt 2675 , inside $w a a C$, to the third base of the fourth codon of wabI (nt 3285), an in-frame 21 bp linker, and nt 4138, inside $w a b I$, to nt 4974, inside waaL, including the last wabI 14 codons. Plasmid $\mathrm{pKO} 3 \Delta w a b J_{\mathrm{C} 3}$ included nt 4581 , inside $w a a L$, to nt 5426, containing the last wabJ 17 codons, an in-frame 21 bp linker, and nt 6357, corresponding to the third base of the 19th codon of wabJ, to nt 7128 , inside wabN. Due to the extensive identity among wabI and wabJ between strains C3 and DL1, the same sets of four primers and DL1 chromosomal DNA were used to construct $\mathrm{pKO} 3 \Delta w a b I_{\mathrm{DL} 1}$ and $\mathrm{pKO} 3 \Delta w a b J_{\mathrm{DL} 1}$. For the same reason, primers used in the construction of pKO3-engineered deletions of $w a b G$ and $w a b H$ in strains $\mathrm{C} 3$ and 52145 were used to construct DL1 $1 w a b G$ and DL1 1 wabH mutants, respectively.

Plasmid constructions for mutant complementation studies.

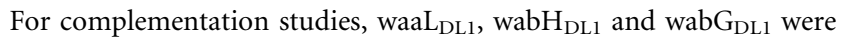
amplified, ligated to pGEM-T Easy (Promega), and transformed into E. coli $\mathrm{DH} 5 \alpha$.

Cell surface extraction, and electrophoresis. $K$. pneumoniae cells grown in trypticase soy broth (TSB) at $37^{\circ} \mathrm{C}$ were dried $(0.6 \mathrm{~g})$ and extracted. The phenol/chloroform/light petroleum ether (PCP) method (Galanos et al., 1969) and a modified phenol/water (PW) procedure (Westphal \& Jann, 1965; Rhan et al., 2003) were used. The PCP and PW methods are used for the extraction of O-PScontaining and -deficient LPS, respectively. The PW extract was processed by two different approaches. First, $100 \mathrm{mg}$ PW extract was purified by hydrophobic chromatography on a Butyl Sepharose column (Pharmacia). The column $(40 \times 2 \cdot 5 \mathrm{~cm})$ was equilibrated with $200 \mathrm{mM}$ sodium acetate $(\mathrm{NaOAc}), \mathrm{pH} 4 \cdot 7$, and eluted initially with $150 \mathrm{ml}$ of the same buffer, and then with $450 \mathrm{ml}$ of a linear gradient to NaOAc: $n$-propanol (50:50, v/v) (Muck et al., 1999). Fractions of $2.5 \mathrm{ml}$ were collected, and monitored for carbohydrates (phenol/sulfuric acid test, $A_{490}$ ). Eluted fractions were pooled, dialysed and freeze-dried, yielding fraction pools 1, 2 and 3, of 11, 22 and $26 \mathrm{mg}$, respectively. Only fraction pools 1 and 3 were further analysed, because fraction pool 2 contained nucleic acid. In the second approach, the water phase obtained was ultracentrifuged $(105000 \mathrm{~g})$ at $15{ }^{\circ} \mathrm{C}$ for $17 \mathrm{~h}$. The supernatant was treated with DNase, RNase and proteinase $\mathrm{K}$ (Sigma) in order to eliminate both nucleic acid and proteins. The sample was dialysed and lyophilized $(20 \mathrm{mg})$, and chromatographed on a Sephacryl S-200 column (Pharmacia).The column was equilibrated with $10 \mathrm{mM}$ Tris buffer, $\mathrm{pH} 8$, containing $1 \cdot 25 \%$ deoxycholate (DOC), $0 \cdot 2 \mathrm{M} \mathrm{NaCl}$ and $5 \mathrm{mM}$ EDTA, and the eluent was monitored with a Knauer differential refractometer. On the basis of the chromatographic profile, the eluted fractions were pooled, dialysed and lyophilized. Fraction pools 1 and 2, of 7 and $3 \mathrm{mg}$, respectively, were obtained. For screening purposes, LPS was obtained after proteinase-K digestion of whole cells (Hitchcock \& Brown, 1983). PCP and PW cell-surface extracts, and LPS preparations obtained by the method of Hitchcock \& Brown (1983), were separated by SDS-PAGE or Tricine $\{\mathrm{N}$-[2-hydroxy-1,1-bis(hydroxymethyl) ethyl]glycine SDS-PAGE, and visualized by silver staining, as described (Pradel \& Schnaitman, 1991; Tsai \& Frasch, 1982).

Isolation of oligosaccharides (OS). The LPS-containing PCP extract from K. pneumoniae $52145 \Delta$ waaL wabH $(15 \mathrm{mg}$ ) was hydrolysed with $1 \%$ acetic acid $\left(100{ }^{\circ} \mathrm{C}\right.$ for $\left.1 \mathrm{~h}\right)$. The resulting precipitate $(6 \mathrm{mg})$ was removed by centrifugation $(10000 \mathrm{~g})$, and the supernatant $(4 \mathrm{mg})$ was analysed by MS. Another PCP-LPS sample $(15 \mathrm{mg})$ was deacylated and purified, as described (Holst et al., 1991, 1993), obtaining $2 \mathrm{mg}$ alditol OS. Peaks 1 and 3 from Butyl Sepharose chromatography were hydrolysed separately with $1 \%$ acetic acid, containing $0 \cdot 1 \%$ SDS, at $100{ }^{\circ} \mathrm{C}$ for $3 \mathrm{~h}$. After cooling, the samples were centrifuged $(10000 \mathrm{~g})$ for $20 \mathrm{~min}$. The supernatants were lyophilized, washed with ethanol, and analysed by MS. Samples (1 mg) of peaks 1 and 2 of gel-filtration chromatography were separately stirred in anhydrous hydrazine $(0.5 \mathrm{ml})$ at $37^{\circ} \mathrm{C}$ for $1.5 \mathrm{~h}$ (Holst et al., 1991). The reaction mixtures were cooled in an ice bath, and cold acetone was added in small portions until the precipitation was complete. The samples were then centrifuged $\left(6300 \mathrm{~g}, 4{ }^{\circ} \mathrm{C}, 15 \mathrm{~min}\right)$, the pellets were washed twice with cold acetone, dissolved in water for lyophilization, and analysed by matrix-assisted laser desorption ionization time-of-flight (MALDI-TOF) MS.

Glycosyl and lipid analysis. Samples $(1 \mathrm{mg})$ of PCP and PW extracts were dried over $\mathrm{P}_{2} \mathrm{O}_{5}$ overnight, and treated with $1 \mathrm{M} \mathrm{HCl} /$ $\mathrm{CH}_{3} \mathrm{OH}(1 \mathrm{ml})$ at $80^{\circ} \mathrm{C}$ for $20 \mathrm{~h}$. The crude reactions were extracted 
twice with hexane; the two extracts were pooled, dried under a stream of air, and treated with acetic anhydride $(100 \mu \mathrm{l})$ at $100^{\circ} \mathrm{C}$ for $15 \mathrm{~min}$, and the acetylated fatty acids methyl esters were analysed by GC-MS. The remaining methanol phase after hexane extraction was neutralized with $\mathrm{Ag}_{2} \mathrm{CO}_{3}$, dried, acetylated, and the methylglycoside derivatives were analysed by GC-MS. The same analysis was performed on relevant fractions from Butyl Sepharose and Sephacryl gel chromatography.

GC-MS analysis. Alditol acetates, methyl glycoside acetates, partially methylated alditol acetates and acetylated methyl esters lipids were analysed on a Agilent Technologies 5973N MS instrument equipped with a $6850 \mathrm{~A}$ Gas Chromatograph and an RTX-5 capillary column (Restek; $30 \mathrm{~m} \times 0.25 \mathrm{~mm}$ i.d., flow rate $1 \mathrm{ml} \mathrm{min}^{-1}$, helium carrier gas), as previously described (Izquierdo et al., 2002).

MS studies. Positive- and negative-ion MALDI-TOF spectra were acquired on a Voyager DE-PRO instrument (Applied Biosystems) equipped with a delayed extraction ion source, in both linear and reflector modes. Ion acceleration voltage was $20 \mathrm{kV}$, grid voltage was $14 \mathrm{kV}$, mirror voltage ratio was $1 \cdot 12$, and delay time was $100 \mathrm{~ns}$. Samples were irradiated at a frequency of $5 \mathrm{~Hz}$ by $337 \mathrm{~nm}$ photons from a pulsed nitrogen laser. Mass calibration was obtained with a malto-oligosaccharide mixture from corn syrup (Sigma). A solution of 2,5-dihydroxybenzoic acid in $20 \% \mathrm{CH}_{3} \mathrm{CN}$ in water at a concentration of $25 \mathrm{mg} \mathrm{ml}^{-1}$ was used as the MALDI matrix. Matrix solution $(1 \mu \mathrm{l})$ and sample $(1 \mu \mathrm{l})$ were premixed, and then deposited on the target. The droplet was allowed to dry at an ambient temperature. Spectra were calibrated and processed under computer control using the Applied Biosystems Data Explorer software.

Murine pneumonia model. The experiments were performed as described (Cortés et al., 2002). Briefly, ICR-CDI mice (Harlan Ibérica) were anaesthetized, and intubated intratracheally with a blunt-ended needle. Approximately $10^{7}$ c.f.u. of exponentially growing K. pneumoniae cells were suspended in $50 \mu \mathrm{l}$ PBS, and inoculated through the blunt-ended needle. The mice were observed daily, and bacteraemia was assessed on days 2, 4 and 6 by culturing blood obtained from the tail vein (approx. $20 \mu \mathrm{l}$ ) on LB agar. Lung and spleen tissues from surviving animals and dead animals were aseptically removed, homogenized, and plated for quantitative bacterial cultures. Each experiment was performed with nine animals.

\section{RESULTS}

\section{K. pneumoniae K2 capsule association to the cell surface does not require the core LPS O-PS : lipid-A-core ligase}

Two different core LPS types have been reported in $K$. pneumoniae (Regué et al., 2005b; Vinogradov \& Perry, 2001) (Fig. 1a, b). Knowledge of the role of K. pneumoniae genes involved in core LPS biosynthesis (Frirdich et al., 2004; Izquierdo et al., 2002, 2003; Regué et al., 2001, 2005a, b) enabled the construction of a set of isogenic non-polar waa mutants in K. pneumoniae strains producing either type 1 [C3 (O8: K66) and DL1 (O1: K1)] or type 2 [52145 (O1:K2)] core LPS. The waaL gene encodes the O-PS:lipid-A-core ligase, and, as expected, these waaL mutants were devoid of $\mathrm{O}-\mathrm{PS}$, as determined by SDS-PAGE analysis of the corresponding LPS preparations (see Fig. 2, lane 2, for $52145 \Delta w a a L$ ).

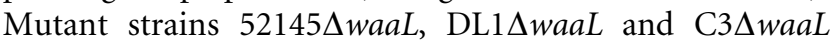
were sensitive to capsule-specific phages $\phi 2$ (K2) (Table 2), $\phi 1$ (K1) and FC3-9 (K66), respectively. No difference in capsule-specific phage e.o.p. was found between each waaL mutant and its isogenic parent strain, suggesting that the level of functional capsule production is independent of the O-PS ligase. To demonstrate that the waaL mutants and their isogenic parent strains produced the same capsular type, ELISAs using specific capsular antibodies were performed. Cells from mutant strains $52145 \Delta$ waaL (Table 2), DL1 1 waaL and C3 3 waaL reacted with anti-K2, $-\mathrm{K} 1$ and -K66 antibodies, respectively. In addition, the presence of cell-bound capsule was observed in the three waaL mutant strains in electron microscope (EM) studies (data not shown). Each mutant was complemented by introduction of the corresponding wild-type waaL. These results strongly suggest that the O-PS ligase is not involved in the association of the K1, K2 and K66 capsule polysaccharides to the cell surface in K. pneumoniae.

\section{K. pneumoniae core LPS galacturonic acid (GaIA) residues are essential for $\mathrm{K} 2$ capsule association to the cell surface}

Non-polar mutants were generated in each gene predicted to be involved in core-LPS biosynthesis, with the exception of gmhD (ADP-Hep epimerase) and waaA (CMP-Kdo transferase) (Fig. 1a). These mutants were constructed in strain

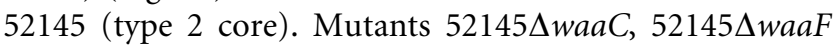
and $52145 \Delta w a b G$ were resistant to phage $\phi 2$, and their cells did not react with anti-K2 capsule serum in ELISAs using capsule K2-specific antibodies. But, K2-PS-like material was detected in the culture supernatants of these mutants by ELISA (Table 2). These results suggest that these three mutants synthesize capsular polysaccharide, but that it cannot be attached to the cell surface. By contrast, mutants $52145 \Delta w a b H, 52145 \Delta w a b K$ and $52145 \Delta w a b M$ were phage $\phi 2$ sensitive, and contained cell-associated K2-PS (Table 2). Comparison of the known core-OS from mutants 52145 $w a b H$ (Fig. 1c) and 52145 $\Delta a b G$ (Fig. 1d) suggests an essential role for the core OS GalA residues in $\mathrm{K} 2$ interaction with the cell surface.

\section{Capsule-K2-LPS co-elution}

Cells from $52145 \Delta$ wabH waaL double mutant were extracted by the PCP method (Galanos et al., 1969). Chemical composition of this PCP extract showed the presence of the characteristic core LPS sugars 3-deoxy-D-manno-oct-2ulosonic acid (Kdo), L-glycero-D-manno-heptopyranose (Hep), D-glucopyranose (Glc) and GalA. The same cells were first treated with PCP, and then with a modified PW procedure (Rahn et al., 2003). The PW extract contained glucuronic acid (GlcA) and mannose (Man) from the K2 capsule (Corsaro et al., 2005), in addition to core LPS sugars. Protein was not detected in these preparations.

Hydrophobic chromatography of the PW extract on a Butyl Sepharose column (Pharmacia) separated this material into three major peaks (1, 2 and 3) (Fig. 3a). Peak 2 was discarded because it contained nucleic acid only. Chemical analysis of peaks 1 and 3 revealed the presence of both $\mathrm{K} 2$ 
(a)

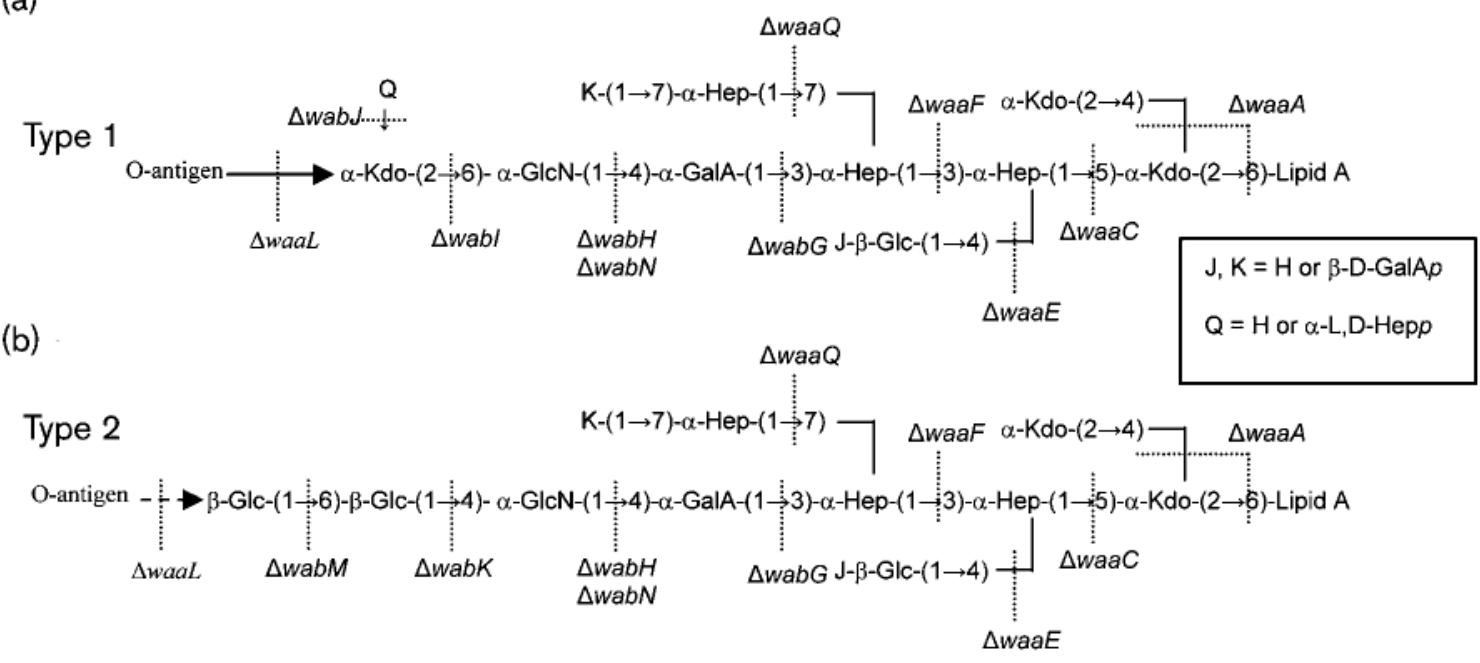

Klebsiella pneumoniae 52145 (type 2 core)

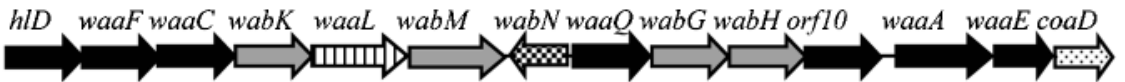

Klebsiella pneumoniae $\mathrm{C} 3$ (type 1 core)

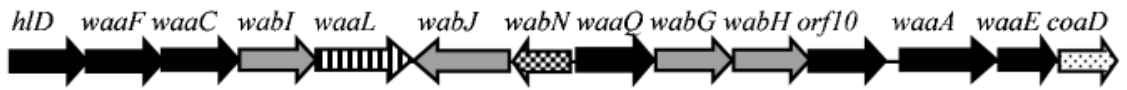

(c)

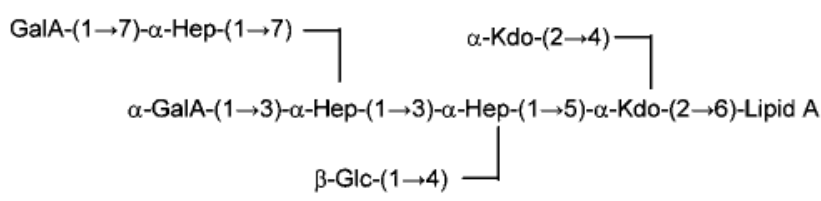

(d)

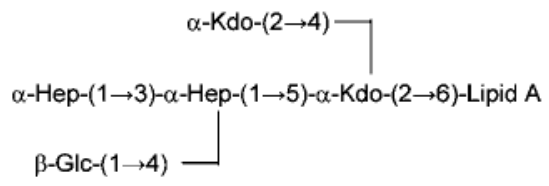

Fig. 1. K. pneumoniae core OS structures. (a, b) Core type 1 and 2 structures from K. pneumoniae (Regué et al., 2005b; Vinogradov \& Perry, 2001), and genes involved in the synthesis of type 1 and 2 core LPS (Frirdich et al., 2004; Izquierdo et al., 2002, 2003; Regué et al., 2001, 2005a, b). Structures of core OS from K. pneumoniae 52145 waaL wabH (Regué et al., 2005a) (c), and waaL wabG (Izquierdo et al., 2003) (d). Depending on the K. pneumoniae strain, residues J and $K$ could be hydrogen $(H)$ or GalA, and residue $\mathrm{Q}$ could be $\mathrm{H}$ or Hep (Vinogradov \& Perry, 2001). The bold broken arrow (b) denotes that the O-antigen attachment site deduced from the analysis of $\Delta w a b K$ and $\Delta w a b M$ mutants (Regué et al., 2005b).

and core-LPS residues. The integration results of GC-MS analysis showed a GalA: GlcA ratio of $0 \cdot 25$ for peak 1 , whereas this ratio was $3 \cdot 3$ for peak 3 , indicating that K2-PS (GlcA) was more abundant in peak 1 while LPS (GalA) was more abundant in peak 3 . These results suggest that at least $\mathrm{K} 2$ and core LPS co-elute in the same peaks (Fig. 3b). Material from both peaks 1 and 3 was characterized by hydrolysis with $1 \%$ acetic acid, followed by positive-ion MALDI-TOF and ${ }^{1} \mathrm{H}-\mathrm{NMR}$ analyses of the recovered OS.
The comparison of the MALDI-TOF spectrum of the acetic acid hydrolysis product of purified LPS with those of peaks 1 and 3 suggested the co-elution of K2 and LPS for peak 3 (Fig. 4). The assignment of core-LPS signals is summarized in Fig. 4 (insert above figure), and was obtained as previously reported (Regué et al., 2005b). In the mass spectrum of peak 1 (Fig. 4), the difference $(\Delta)$ between the clusters of signals corresponded to hexose or hexuronic acid (162 or $176 \mathrm{Da}$ ), which are constituents of the K2 


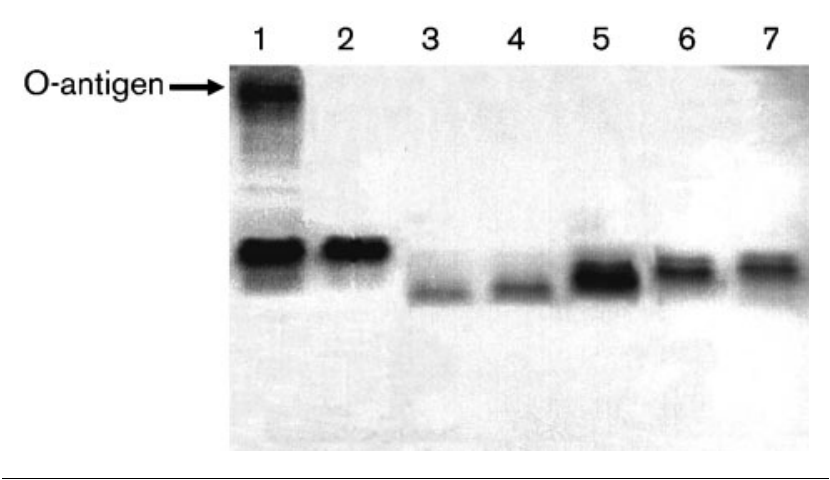

Fig. 2. Analysis of LPS by Tricine SDS-PAGE. LPS samples from wild-type $K$. pneumoniae 52145 (lane 1), and core-LPS

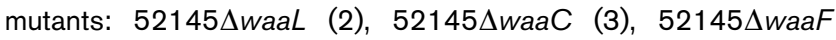

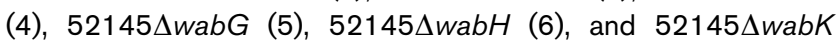
(7). The arrow denotes the region of wild-type LPS containing a high degree of polymerized O-antigen.

capsule. In the mass spectrum of peak 3 , signals of core OS were present, together with those of K2-PS (Fig. 4). By contrast, the comparison of ${ }^{1} \mathrm{H}-\mathrm{NMR}$ spectra of purified K2 structure and acetic-acid-released core LPS with those of peaks 1 and 3 suggest the co-elution of the two polysaccharides in both peaks 1 and 3 (Fig. 5). The absence of core LPS signals in the mass spectrum of peak 1 could be attributable to the low abundance of LPS in this peak, and to a lower ionization ability of the core LPS than that of K2-PS.

Furthermore, the presence of $\mathrm{K} 2$ antigen in peaks 1 and 3 was confirmed by ELISA with specific K2 antiserum. In peaks 1 and 3, no signals corresponding to core OS covalently linked to one or more repetitive units of K2-PS were detected by the MS experiments, suggesting a non-covalent association between K2-PS and core LPS.
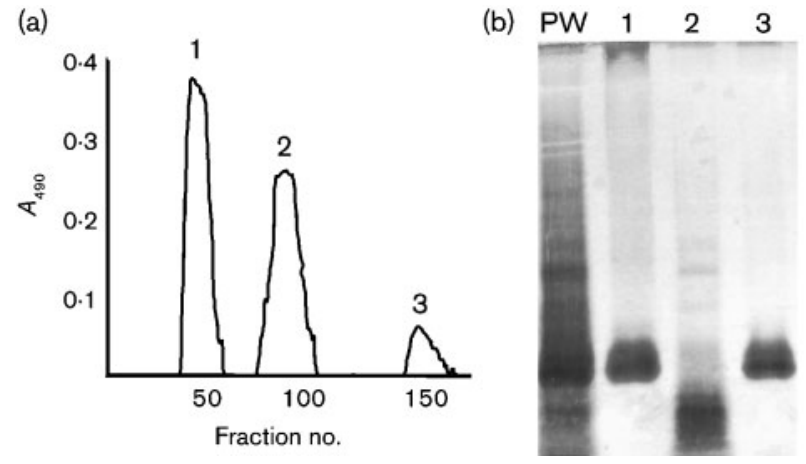

Fig. 3. K2-capsule-LPS co-elution. (a) Butyl Sepharose chromatogram of PW extract from strain $52145 \Delta$ waal wabH. (b) SDS-PAGE analysis of PW extract and chromatographic peaks 1,2 and 3.

\section{Capsule-K2-LPS ionic interaction}

To determine how the $\mathrm{K} 2$ polysaccharide was associated to the core LPS, the 52145 $\Delta$ wabH waaL PW extract was treated with DNase, RNase and proteinase $\mathrm{K}$, and further purified by high-speed centrifugation. This preparation was subjected to gel-filtration chromatography on a Sephacryl S-200 column (Pharmacia) using as the eluent a buffer with an increased ionic strength $(0 \cdot 1 \mathrm{M} \mathrm{NaCl}$ and $10 \mathrm{mM}$ Tris), which contained the metal-ion chelator EDTA, and the dissociating detergent DOC (see Methods). This approach allowed the fractionation of the PW extract into two main peaks (1 and 2) (Fig. 6a). SDS-PAGE analysis showed the presence of only LPS molecules in peak 2, while in peak 1 , both K2 and LPS molecules were present (Fig. 6b). Chemical analysis confirmed the presence of LPS residues in peak 2, and of both $\mathrm{K} 2$ and LPS residues in peak 1 . Both peak 1 and 2

Table 2. Sensitivity to bacteriophage $\phi 2$, and ELISAs with anti-K2 capsule serum of $K$. pneumoniae 52145 and mutant derivatives

\begin{tabular}{|lccc|}
\hline Strain & $\begin{array}{c}\text { Sensitivity to } \\
\text { bacteriophage } \boldsymbol{\phi} \text { 2 (e.o.p.) }\end{array}$ & Reactivity $\left(\boldsymbol{A}_{\mathbf{4 0 5}}\right)$ of anti-K2-capsule serum against: ${ }^{*}$ \\
\cline { 3 - 4 } & 1 & Whole cells $\dagger$ & Supernatant $\ddagger$ \\
\hline 52145 & $0 \cdot 99$ & $1 \cdot 76 \pm 0 \cdot 18$ & $0 \cdot 25 \pm 0 \cdot 04$ \\
$52145 \Delta$ waaL & $0 \cdot 98$ & $1 \cdot 72 \pm 0 \cdot 14$ & $0 \cdot 19 \pm 0 \cdot 03$ \\
$52145 \Delta$ wabK & $0 \cdot 99$ & $1 \cdot 71 \pm 0 \cdot 15$ & $0 \cdot 21 \pm 0 \cdot 05$ \\
$52145 \Delta w a b M$ & $0 \cdot 98$ & $1 \cdot 79 \pm 0 \cdot 13$ & $0 \cdot 22 \pm 0 \cdot 02$ \\
$52145 \Delta w a b H$ & 0 & $1 \cdot 68 \pm 0 \cdot 10$ & $0 \cdot 20 \pm 0 \cdot 05$ \\
$52145 \Delta w a b G$ & 0 & $<0 \cdot 1$ & $0 \cdot 87 \pm 0 \cdot 09$ \\
$52145 \Delta w a a F$ & 0 & $<0 \cdot 1$ & $0 \cdot 69 \pm 0 \cdot 08$ \\
$52145 \Delta w a a C$ & & $<0 \cdot 1$ & $0 \cdot 74 \pm 0 \cdot 07$ \\
\hline
\end{tabular}

* Data are means $( \pm \mathrm{SD})$ derived from at least three independent experiments.

$\dagger$ The number of whole cells used was approximately $10^{6}$ c.f.u.

$\ddagger$ Supernatants were obtained from overnight cultures that had been centrifuged and filtered to remove bacterial cells, and then concentrated tenfold. 

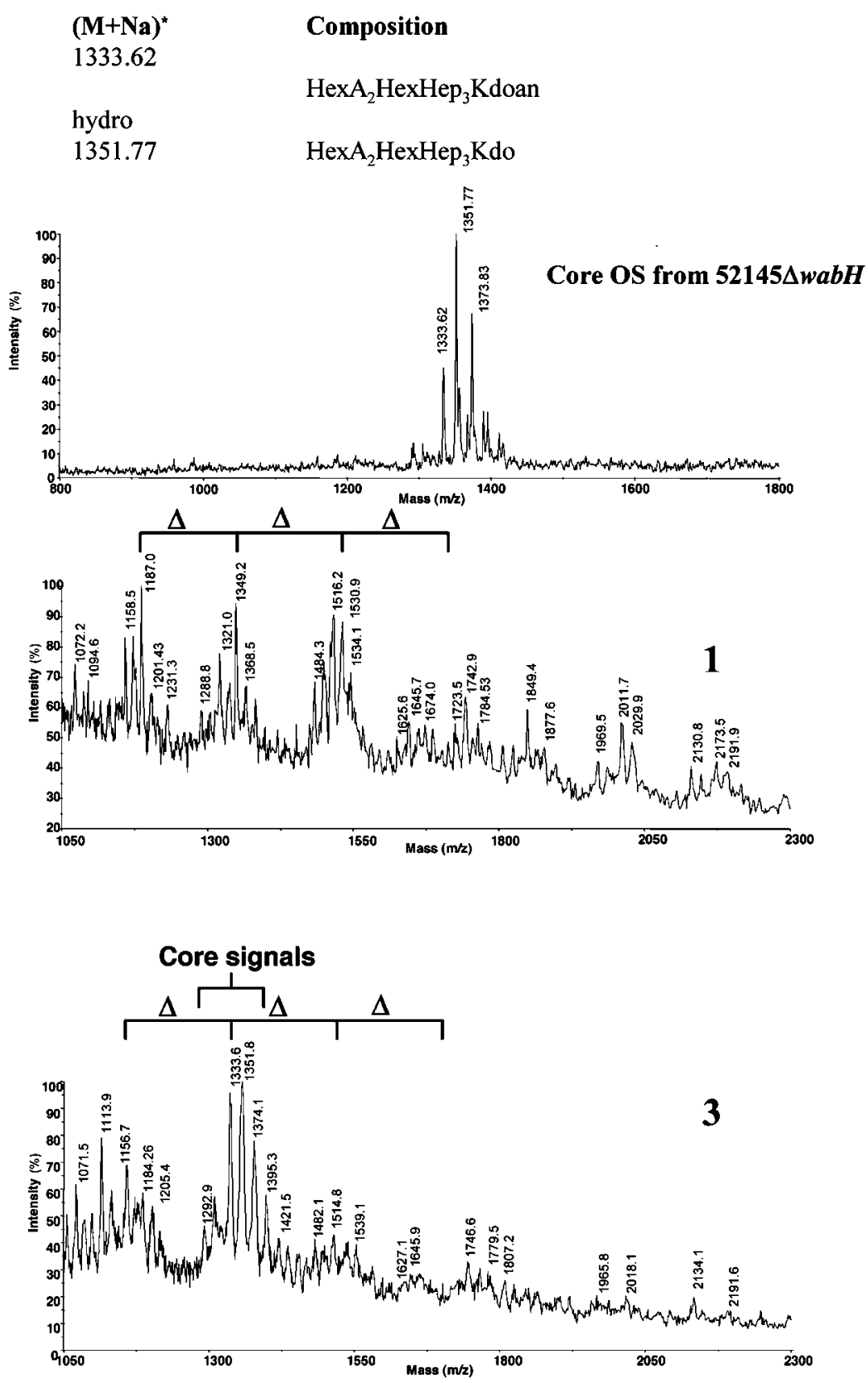

Fig. 4. Positive-ion MALDI-TOF spectra of Butyl Sepharose chromatographic peaks. Samples were hydrolysed in $1 \%$ acetic acid, and subjected to MALDI-TOF analysis. Spectra from core LPS and peaks 1 and 3 (see Fig. 3), separated by Butyl Sepharose chromatography. Assignment of core LPS signals is summarized in the inserted text. $\Delta$, Difference between the clusters of signals attributable to Hex (162 Da) and/or HexA (176 Da) of K2-PS.

samples were characterized by $O$-delipidation and negativeion MALDI-TOF MS analysis (Fig. 6). Comparison of mass spectra signals of peak 2 and purified $O$-deacylated LPS showed the presence of only $O$-deacylated LPS in this peak (Fig. 7). Signals corresponding to K2-PS and O-deacylated LPS were present in peak 1 (Fig. 7). In addition, ELISA analyses of peaks 1 and 2 with specific $\mathrm{K} 2$ antiserum showed the presence of $\mathrm{K} 2$ molecules in peak 1 only, thus confirming the above results. The complete separation between LPS and
K2 antigen was achieved by three successive gel-filtration chromatographs of the peak 1 material in the presence of EDTA and DOC (Fig. 8). This result indicates that the ionic strength and the amount of EDTA are crucial to completely remove cation bridges between LPS and K2 capsule.

There was no difference in the spectra of outer-membrane protein (OMP) bands seen in wild-type 52145, and 52145 $\Delta$ waaL and $52145 \Delta$ wabH mutants. However, some changes in 
(a)

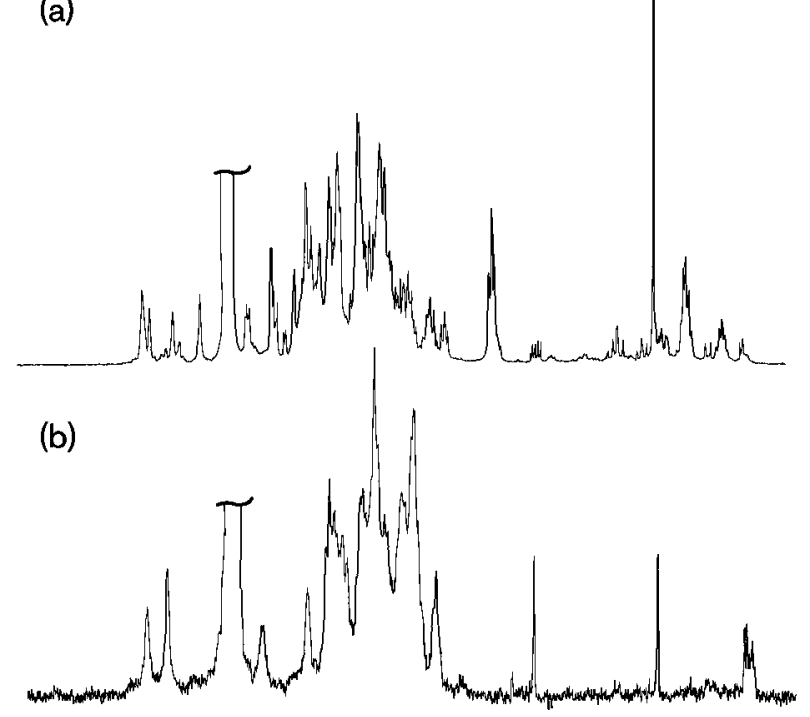

(c)

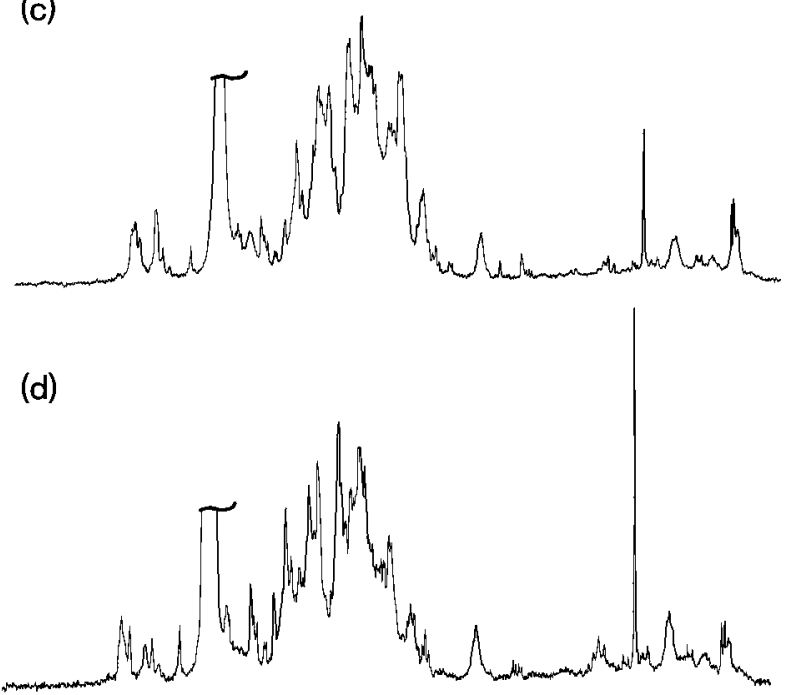

Fig. 5. ${ }^{1} \mathrm{H}$ NMR spectra in $\mathrm{D}_{2} \mathrm{O}$ at $400 \mathrm{MHz}$ of (a) PCP-LPS acetic acid hydrolysis product from mutant $52145 \Delta$ waal wabH, (b) K2-PS, and (c) peak 1 and (d) peak 3 from the Butyl Sepharose chromatogram.

the relative intensities of the minor OMPs were observed, but the major OMPs remained unchanged in their relative intensity [OmpK36, K35, OmpA-like, OmpK17 (Albertí et al., 1995; Climent et al., 1997; Hernández-Allés et al., 1999; Martínez-Martínez et al., 1996)]. Nevertheless, truncation of the core LPS beyond the outer core GalA residue in the $w a b H$ mutant might alter the presence or the topology of other outer-membrane (OM) minor molecules, which could block capsule attachment to other(s) target(s) in the OM. To test this possibility, $52145 \Delta w a a L$ cells, containing

(a)

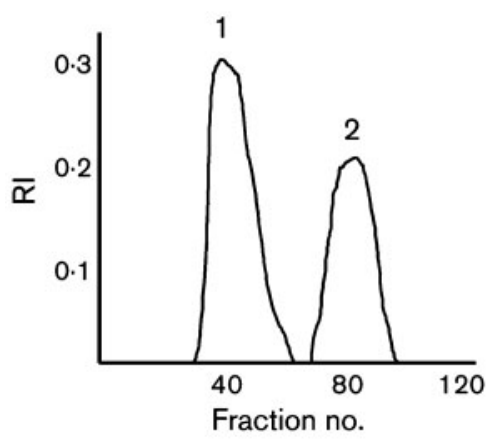

(b)

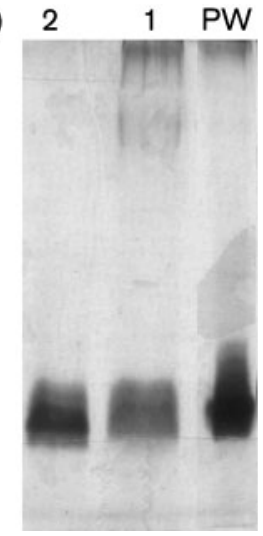

Fig. 6. K2-capsule-LPS ionic interaction. (a) Sephacryl gelfiltration chromatography with EDTA and DOC (see Methods)

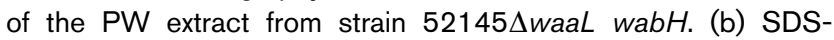
PAGE analysis of the PW extract, and chromatographic peaks 1 and 2 .

full-length type 2 core OS, were extracted successively with PCP and PW. PW extracts from these cells also contained LPS and K2-PS co-purifying through hydrophobic chromatography. Both LPS and K2-PS were fully separated into two peaks after three consecutive gel-filtration chromatography assays in the presence of EDTA and DOC, as determined by SDS-PAGE, ELISA and chemical analysis (data not shown). This result suggests that the postulated ionic interaction between core OS and K2-PS is not due to $5245 \Delta w a b H$ mutant pleiotropic effects on the OM.

\section{Other Klebsiella capsular types (K1 and K66)- core-LPS interaction}

To study if the K2-core-LPS interaction is a feature shared by other K. pneumoniae capsular serotypes, core-LPS-deficient mutants were constructed in K. pneumoniae strains C3 (O8: K66) and DL1 (O1:K1). The capsular phenotypes of these mutants were determined using capsule K66- and K1specific bacteriophages FC3-9 and $\phi 1$, respectively, ELISAs with specific antiserum against K66 and K1, and EM studies. Strains with mutations in the genes waaC (C3AwaaC, DL1 1 waaC), waaF (C3 $3 w a a F, D L 1 \Delta w a a F)$ and $w a b G$ $(\mathrm{C} 3 \Delta w a b G, \mathrm{DL} 1 \Delta w a b G)$ were devoid of cell-surfaceassociated capsule, although K-PS-like material was detected in their culture supernatants by ELISA. Strains with mutations in the genes wabH $(\mathrm{C} 3 \Delta w a b H, \mathrm{DL} 1 \Delta w a b H), w a b I$

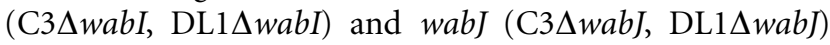
were capsulated. Double-deletion mutants C3 3 waaL wabG and DL1 $\Delta$ waaL wabG were non-capsulated, while C3 3 waaL wabH and DL1 1 waaL wabH contained cell-associated K66and K1-PS, respectively. These results suggest that capsulecore-LPS interaction could be a general phenomenon in $K$. pneumoniae, because this interaction determines the presence of cell-associated capsule for the studied capsular types K1, K2 and K66. Furthermore, the capsule-core-LPS interaction appears to require the core OS GalA residues. 

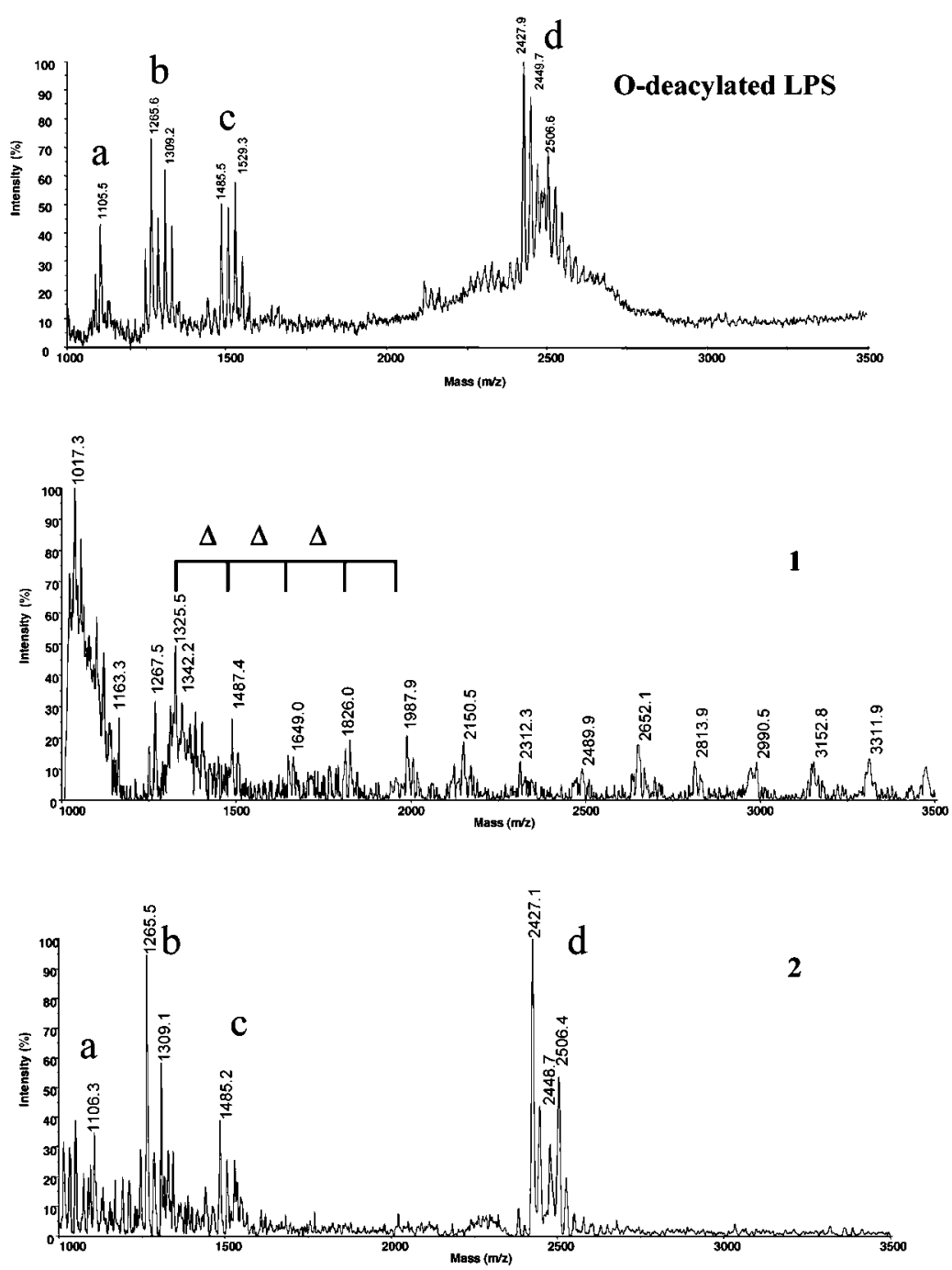

Fig. 7. Negative-ion MALDI-TOF spectra of Sephacryl gel-filtration chromatographic peaks. Samples were O-deacylated, and subjected to MALDI-TOF analysis (see Methods). Spectra from O-deacylated LPS, and peaks 1 and 2 separated by Sephacryl gel filtration, are shown. Assignment of O-deacylated LPS signals: $a, b$ and c, cluster of pseudomolecular ion peaks of species consisting of diacylLipidAKdoP, diacylLipidAKdoP $\mathrm{P}_{3}$ and diacylLipidAKdo ${ }_{2} \mathrm{P}_{3}$ respectively; $d$, cluster of peaks of species corresponding to diacylLipidAKdo ${ }_{2} \mathrm{P}_{3} \mathrm{Hep}_{3} \mathrm{HexHexA}_{2}$. $\Delta$, difference between the clusters of signals attributable to Hex (162 Da) and/or HexA (176 Da) of K2-PS.

\section{Virulence studies}

Virulence was tested in a murine model of pneumonia by intratracheal injection. When the virulence of the strains was assayed in the murine pneumonia model, we obtained the results shown in Table 3 . The $52145 \Delta w a b G$ mutant was completely avirulent in this model, while $52145 \Delta$ waaL and $52145 \Delta w a b H$ mutants, and the wild-type strain, showed similar values. Introduction of the corresponding genes in the mutants rendered them as virulent as the wild-type
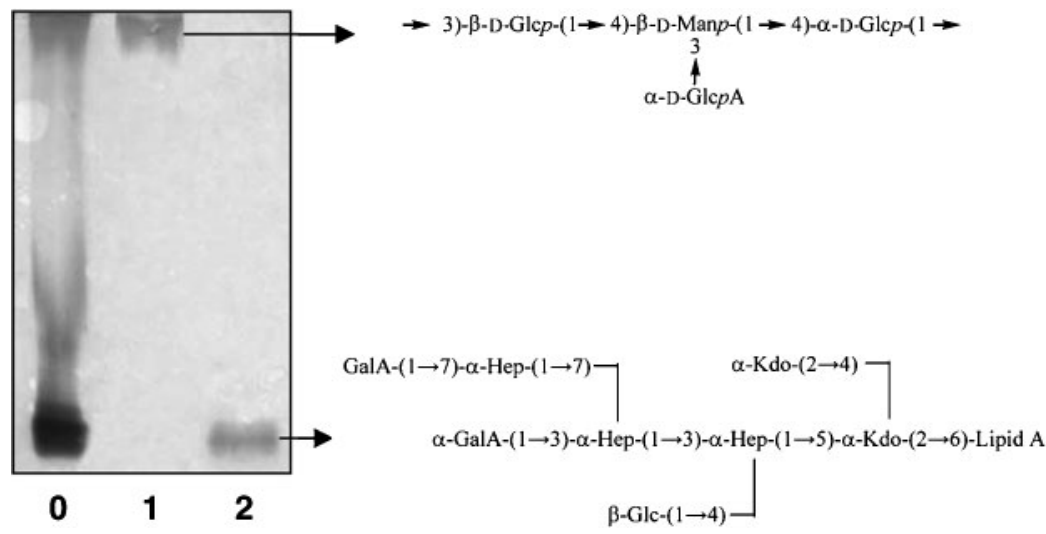

Fig. 8. K2-capsule-LPS complete separation. Peak 1 from the Sephacryl gel filtration chromatography (Fig. 6), containing both K2PS and LPS, was rechromatographed three times using the conditions described in Fig. 6 and Methods. The final two chromatographic peaks were analysed by SDSPAGE. Lanes: 0, starting material; 1, K2-PS; 2 , LPS. Chemical analysis confirmed the complete separation of K2-PS and LPS. 
Table 3. Experimental pneumonia induced by $K$. pneumoniae strains

$P<0.01$ for all comparisons [lung weight, log c.f.u. (g lung) ${ }^{-1}$, mortality and blood or spleen positive cultures] between the strains (twotailed $t$ test).

\begin{tabular}{|c|c|c|c|c|c|}
\hline Strain & $\begin{array}{c}\text { Mean inoculum } \\
\text { (range) }\end{array}$ & $\begin{array}{l}\text { Mean lung } \\
\text { weight }(g)^{*}\end{array}$ & $\begin{array}{c}\text { Mean } \\
\log \text { c.f.u. } \\
\text { (g lung) }^{-1}\end{array}$ & $\begin{array}{c}\text { No. dead } \\
\text { animals/total } \\
\text { no. }(\%)\end{array}$ & $\begin{array}{c}\text { No. positive } \\
\text { cultures/total } \\
\text { no. }(\%) \dagger\end{array}$ \\
\hline 52145 & $1.0 \times 10^{7}\left( \pm 1 \cdot 4 \times 10^{7}\right)$ & $0 \cdot 29 \pm 0 \cdot 11$ & $6 \cdot 11$ & $21 / 36(58)$ & $19 / 36(52)$ \\
\hline $52145 \Delta w a a L L$ & $1 \cdot 0 \times 10^{7}\left( \pm 2 \cdot 1 \times 10^{7}\right)$ & $0 \cdot 35 \pm 0 \cdot 09$ & $6 \cdot 31$ & $10 / 18(55)$ & $10 / 18(55)$ \\
\hline $52145 \Delta w a a L+$ pGEMT & $1 \cdot 7 \times 10^{7}\left( \pm 1 \cdot 6 \times 10^{7}\right)$ & $0 \cdot 37 \pm 0 \cdot 05$ & $6 \cdot 42$ & $10 / 18(55)$ & $10 / 18(55)$ \\
\hline $52145 \Delta w a a L+$ pGEMT-WaaL & $1 \cdot 3 \times 10^{7}\left( \pm 1 \cdot 1 \times 10^{7}\right)$ & $0 \cdot 37 \pm 0 \cdot 11$ & $6 \cdot 09$ & $10 / 18(55)$ & $9 / 18(50)$ \\
\hline $52145 \Delta w a b G$ & $1.9 \times 10^{7}$ & $0 \cdot 18 \pm 0 \cdot 05$ & $<1 \cdot 0$ & $0 / 9(0)$ & $0 / 9(0)$ \\
\hline $52145 \Delta w a b G+$ pGEMT & $1 \cdot 8 \times 10^{7}$ & $0 \cdot 16 \pm 0 \cdot 07$ & $<1 \cdot 0$ & $0 / 9(0)$ & $0 / 9(0)$ \\
\hline $52145 \Delta w a b G+$ pGEMT-WabG & $2 \cdot 2 \times 10^{7}\left( \pm 0 \cdot 5 \times 10^{7}\right)$ & $0 \cdot 27 \pm 0 \cdot 12$ & $5 \cdot 98$ & $10 / 18(55)$ & $9 / 18(50)$ \\
\hline $52145 \Delta w a b H$ & $1 \cdot 6 \times 10^{7}\left( \pm 1 \cdot 2 \times 10^{7}\right)$ & $0 \cdot 33 \pm 0 \cdot 07$ & $6 \cdot 02$ & $9 / 18(50)$ & $9 / 18(50)$ \\
\hline $52145 \Delta w a b H+$ pGEMT & $1 \cdot 3 \times 10^{7}\left( \pm 0 \cdot 9 \times 10^{7}\right)$ & $0 \cdot 31 \pm 0 \cdot 05$ & $6 \cdot 07$ & $10 / 18(55)$ & $10 / 18(55)$ \\
\hline $52145 \Delta w a b H+$ pGEMT-WabH & $1 \cdot 5 \times 10^{7}\left( \pm 1 \cdot 0 \times 10^{7}\right)$ & $0 \cdot 36 \pm 0 \cdot 09$ & $6 \cdot 14$ & $11 / 18(60)$ & $9 / 18(50)$ \\
\hline
\end{tabular}

${ }^{\star}$ Values are given as mean $\pm \mathrm{SD}$.

$\dagger$ Blood or spleen cultures.

strain. However, mutant $52145 \Delta w a b G$ transformed with the plasmid vector alone (pGEMT) remained avirulent in this animal model.

\section{DISCUSSION}

The constitutive cell-associated K-PS is a major pathogenic factor in K. pneumoniae infection, but the basis for its attachment to the cell surface is unknown. In the few studied encapsulated Gram-negative bacteria, K-PS has been proposed to be covalently linked to a lipid moiety, either core lipid A or a glycerolipid. The K-PS association to core lipid A has been suggested to involve the O-PS ligase. Results based on the analysis of three non-polar O-PS ligase (WaaL) mutants showed that in K. pneumoniae this activity is not required for functional K2-PS cell-surface linkage.

K. pneumoniae core-LPS mutants containing the GalA core residues contained functional K2-PS. By contrast, mutants devoid of core GalA residues were devoid of functional K2PS. PCP extraction of waaL wabH mutant did not enable us to recover K2-PS, while PW extraction recovered both LPS and K2-PS. This is in agreement with the amphipathic and hydrophilic natures of LPS and K2-PS, respectively.

Characterization of PW extracts from $K$. pneumoniae $52145 \Delta$ waal wabH showed that K2 capsule and LPS copurify after hydrophobic-interaction chromatography. MS of the chromatographic peaks agreed with a non-covalent association between both molecules. The possibility that phenol used in both extraction methods could hydrolyse the putative ester linkage between K2-PS and core LPS is unlikely since these methods allow the isolation of LPS molecules containing $O$-acylated residues (Knirel \& Kochetkov, 1994).
Gel-filtration chromatography and elution in a buffer with EDTA and DOC enabled the isolation of a chromatographic peak with LPS only, according to chemical composition and MS analysis. The other chromatographic peak containing K2-PS associated to core LPS was fully separated on successive chromatographic assays. The same results were obtained using $52145 \Delta$ waa containing a full-length core OS. These results indicate that the K2-PS is associated to the cell surface by an ionic interaction between K2-PS and core OS. The role of $\mathrm{Mg}^{2+}$ ions in establishing ionic bridges between adjacent LPS molecules through negatively charged core residues has been established (Nikaido \& Vaara, 1985). In a similar way, we suggest that the divalent ions $\mathrm{Mg}^{2+}$ and/or $\mathrm{Ca}^{2+}$ could play a role in the ionic interaction between GlcA (K2-PS) and GalA residues (core OS). This ionic interaction could also explain the formation of the extracellular toxic complex, containing both K2-PS and LPS, in K. pneumoniae (Straus et al., 1985). Furthermore, the similar behaviour of waaL wabH and waaL wabG mutants from K. pneumoniae belonging to capsular serotypes $\mathrm{K} 1$ and $\mathrm{K} 66$ suggests that the capsule-core-LPS ionic interaction is a general K. pneumoniae phenomenon. In the three K. pneumoniae capsular serotypes analysed, the presence of GalA residues in core OS was necessary for capsule association to cell surface.

The effects of the wabG, wabH and waaL mutations in virulence experiments were studied in the $K$. pneumoniae 52145 background because this strain is highly virulent in the model used. The wabG mutant was completely avirulent in the experimental model of pneumonia (Table 3). A similar result was obtained using a non-capsulated mutant of strain 52145 (Cortés et al., 2002). On the other hand, a $K$. pneumoniae waaL mutant, with a full inner and outer core, but devoid of O-antigen, showed similar virulence when compared with the wild-type strain. A similar result was 
obtained for the wabH mutant. All the changes observed in the $K$. pneumoniae wabG and $H$, and waaL mutants were rescued by introduction of the corresponding single wildtype gene, while the introduction of the plasmid vector alone was unable to perform the rescue. The capsule is essential in the K. pneumoniae experimental model of pneumonia, as previously indicated (Cortés et al., 2002). Furthermore, the $\mathrm{K} 2$ present in wabH and waaL mutants enables them to be as virulent as the wild-type strain in the experimental model of pneumonia. These studies clearly confirmed the presence of virulent functional $\mathrm{K} 2$ in waaL and wabH mutants, and its absence in the $w a b G$ mutant.

Summarizing, K. pneumoniae lacks phosphoryl residues in its core, but instead contains GalA as a critical source of negative charge. These results indicate that the negative charge provided by the carboxyl groups of GalA play an essential role in capsule attachment by an ionic interaction. Further work will be necessary to obtain a detailed knowledge of this interaction, which could contribute to the design of more efficient methods of prevention and/or treatment of K. pneumoniae infections.

\section{REFERENCES}

Albertí, S., Rodríquez-Quiñones, F., Schirmer, T., Rummel, G., Tomás, J. M., Rosenbusch, J. P. \& Benedí, V. J. (1995). A porin from Klebsiella pneumoniae: sequence homology, three-dimensional model, and complement binding. Infect Immun 63, 903-910.

Arakawa, Y., Wacharotayankun, R., Nagatsuka, T., Ito, H., Kato, N. \& Otha, M. (1995). Genomic organization of the Klebsiella pneumoniae cps region responsible for serotype $\mathrm{K} 2$ capsular polysaccharide synthesis in virulent strain Chedid. J Bacteriol 177, 1788-1796.

Camprubí, S., Smith, M. A., Tomás, J. M. \& Williams, P. (1992). Modulation of surface antigen expression by Klebsiella pneumoniae in response to growth environment. Microb Pathog 13, 145-155.

Climent, N., Ferrer, S., Rubires, X., Merino, S., Tomás, J. M. \& Regué, M. (1997). Molecular characterization of a $17-\mathrm{kDa}$ outermembrane protein from Klebsiella pneumoniae. Res Microbiol 148, 133-143.

Corsaro, M. M., de Castro, C., Naldi, T., Parrilli, M., Tomás, J. M \& Regué, M. (2005). ${ }^{1} \mathrm{H}$ and ${ }^{13} \mathrm{C}-\mathrm{NMR}$ characterisation and secondary structure of the $\mathrm{K} 2$ polysaccharide of Klebsiella pneumoniae strain 52145. Carbohydr Res 340, 2212-2217.

Cortés, G., Borrell, N., Aztorza, B., Gómez, C., Sauleda, J. \& Albertí, S. (2002). Molecular analysis of the contribution of the capsular polysaccharide and the lipopolysaccharide $\mathrm{O}$ side chain to the virulence of Klebsiella pneumoniae in a murine model of pneumonia. Infect Immun 70, 2583-2590.

Emori, T. G. \& Gaynes, R. P. (1993). An overview of nosocomial infections, including the role of the microbiology laboratory. Clin Microbiol Rev 6, 428-442.

Frirdich, E., Vinogradov, E. \& Whitfield, C. (2004). Biosynthesis of a novel 3-deoxy-D-manno-oct-ulosonic acid-containing outer core oligosaccharide in the lipopolysaccharide of Klebsiella pneumoniae. J Biol Chem 279, 27928-27940.

Galanos, C., Lüderitz, O. \& Westphal, O. (1969). A new method for the extraction of R lipopolysaccharides. Eur J Biochem 9, 245-249.
Gotschlich, E. C., Fraser, B. A., Nishimura, O., Robbins, J. B. \& Liu, T.-Y. (1981). Lipid on capsular polysaccharides of Gram-negative bacteria. J Biol Chem 256, 8915-8921.

Hansen, D. S., Mestre, F., Albertí, S. \& 7 other authors (1999). Klebsiella pneumoniae lipopolysaccharide $\mathrm{O}$ typing: revision of prototype strains and O-group distribution among clinical isolates from different sources and countries. J Clin Microbiol 37, 56-62.

Helander, I. M., Kato, Y., Kilpelainen, I., Kostiainen, R., Lindner, B., Nummila, K., Sugiyama, T. \& Yokochi, T. (1996). Characterization of lipopolysaccharides of polymyxin-resistant and polymyxin-sensitive Klebsiella pneumoniae O3. Eur J Biochem 237, 272-278.

Hernández-Allés, S., Albertí, S., Alvarez, D., Domenech-Sánchez, A., Martinez-Martinez, L., Gil, J., Tomás, J. M. \& Benedí, V. J. (1999). Porin expression in clinical isolates of Klebsiella pneumoniae. Microbiology 145, 673-679.

Hervás, J. A., Alomar, A., Salvá, F., Reina, J. \& Benedi, V. J. (1993). Neonatal sepsis and meningitis in Mallorca (Spain), 1977-1991. Clin Infect Dis 16, 719-724.

Hitchcock, P. J. \& Brown, T. M. (1983). Morphological heterogeneity among Salmonella lipopolysaccharide chemotypes in silver-stained polyacrylamide gels. J Bacteriol 154, 269-277.

Holst, O., Brade, L., Kosma, P. \& Brade, H. (1991). Structure, serological specificity, and synthesis of artificial glycoconjugates representing the genus-specific lipopolysaccharide epitope of Chlamydia spp. J Bacteriol 173, 1862-1866.

Holst, O., Broer, W., Thomas-Oates, J. E., Mamat, U. \& Brade, H. (1993). Structural analysis of two oligosaccharide bisphosphates isolated from the lipopolysaccharide of a recombinant strain of Escherichia coli F515 (Re chemotype) expressing the genus-specific epitope of Chlamydia lipopolysaccharide. Eur J Biochem 214, 703-710.

Izquierdo, L., Abitiu, N., Coderch, N., Hita, B., Merino, S., Gavín, R., Tomás, J. M. \& Regué, M. (2002). The inner-core lipopolysaccharide biosynthetic waaE gene: function and genetic distribution among some Enterobacteriaceae. Microbiology 148, 3485-3496.

Izquierdo, L., Coderch, N., Piqué, N., Bedini, E., Corsaro, M. M., Merino, S., Fresno, S., Tomas, J. M. \& Regué, M. (2003). The Klebsiella pneumoniae $w a b G$ gene: its role in the biosynthesis of the core lipopolysaccharide and virulence. J Bacteriol 185, 7213-7221.

Jann, K., Dengler, T. \& Jann, B. (1992). Core-lipid A on the K40 polysaccharide of Escherichia coli O8:K40:H9, a representative of group I capsular polysaccharides. Zentralbl Bakteriol 276, 196-204.

Kelly, R. F., Severn, W. B., Richards, J. C., Perry, M. B., MacLean, L. L., Tomás, J. M., Merino, S. \& Whitfield, C. (1993). Structural variation in the O-specific polysaccharides of Klebsiella pneumoniae serotype $\mathrm{O} 1$ and $\mathrm{O} 8$ lipopolysaccharide: evidence for clonal diversity in $\mathrm{rfb}$ genes. Mol Microbiol 10, 615-625.

Knirel, Y. A. \& Kochetkov, N. K. (1994). The structures of lipopolysaccharides of Gram-negative bacteria. III. The structure of O-antigens: a review. Biochemistry 59, 1325-1383.

Kuo, S.-C., Doelling, V. W., Graveline, J. F. \& McCoy, D. W. (1985). Evidence for covalent attachment of phospholipid to the capsular polysaccharide of Haemophilus influenzae type b. J Bacteriol 163, 769-773.

Lai, Y.-C., Peng, H.-L. \& Chang, H.-Y. (2003). RmpA2, an activator of capsule biosynthesis in Klebsiella pneumoniae CG43, regulates K2 cps gene expression at the transcriptional level. J Bacteriol 185, 788-800.

Link, A. J., Phillips, D. \& Church, G. M. (1997). Methods for generating precise deletions and insertions in the genome of wildtype Escherichia coli: application to open reading frame characterization. J Bacteriol 179, 6228-6237.

Martínez-Martínez, L., Hernández-Allés, S., Albertí, S., Tomás, J. M., Benedí, V. J. \& Jacoby, G. A. (1996). In vivo selection of 
porin-deficient mutants of Klebsiella pneumoniae with increased resistance to cefoxitin and expanded-spectrum-cephalosporins. Antimicrob Agents Chemother 40, 342-348 (comment).

Miller, J. H. (1972). Experiments in Molecular Genetics. Cold Spring Harbor, NY: Cold Spring Harbor Laboratory.

Muck, A., Ramm, M. \& Hamburger, M. (1999). Efficient method of highly purified lipopolysaccharides by hydrophobic interaction chromatography. J Chromatogr B Biomed Sci Appl 732, 39-46.

Nassif, X., Fournier, J. M., Arondel, J. \& Sansonetti, P. J. (1989). Mucoid phenotype of Klebsiella pneumoniae is a plasmid-encoded virulence factor. Infect Immun 57, 546-552.

Nikaido, H. \& Vaara, M. (1985). Molecular basis of bacterial outer membrane permeability. Microbiol Rev 49, 1-32.

Ørskov, I. \& Ørskov, F. (1984). Serotyping of Klebsiella. In Methods in Microbiology, pp. 143-164. Edited by T. Bergan. London: Academic Press.

Pradel, E. \& Schnaitman, C. A. (1991). Effect of $r f a H(s f r B)$ and temperature on expression of $r f a$ genes of Escherichia coli K-12. J Bacteriol 173, 6428-6431.

Rahn, A., Beis, K., Naismith, J. H. \& Whitfield, C. (2003). A novel outer membrane protein, Wzi, is involved in surface assembly of the Escherichia coli K30 group 1 capsule. J Bacteriol 185, 5882-5890.

Regué, M., Climent, N., Abitiu, N., Coderch, N., Merino, S., Izquierdo, L., Altarriba, M. \& Tomás, J. M. (2001). Genetic characterization of the Klebsiella pneumoniae waa gene cluster, involved in core lipopolysaccharide biosynthesis. J Bacteriol 183, 3564-3573.

Regué, M., Hita, B., Piqué, N., Izquierdo, L., Merino, S., Fresno, S., Benedi, V. J. \& Tomás, J. M. (2004). A gene (uridinediphosphate galacturonate 4-epimerase) is essential for Klebsiella pneumoniae virulence. Infect Immun 72, 54-61.

Regué, M., Izquierdo, L., Fresno, S. \& 7 other authors (2005a). The incorporations of glucosamine to enterobacterial core LPS: two enzymatic steps are required. J Biol Chem 280, 36648-36656.
Regué, M., Izquierdo, L., Fresno, S. \& 7 other authors (2005b). A second outer-core region in Klebsiella pneumoniae lipopolysaccharide. J Bacteriol 187, 4198-4206.

Sambrook, J., Fritsch, E. F. \& Maniatis, T. (1989). Molecular Cloning: a Laboratory Manual, 2nd edn. Cold Spring Harbor, NY: Cold Spring Harbor Laboratory.

Straus, D. C., Atkisson, D. L. \& Garner, C. W. (1985). Importance of a lipopolysaccharide-containing extracellular toxic complex in infections produced by Klebsiella pneumoniae. Infect Immun 50, 787-795.

Süsskind, M., Muller-Loennies, S., Nimmich, W., Brade, H. \& Holst, O. (1995). Structural investigation on the carbohydrate backbone of the lipopolysaccharide from Klebsiella pneumoniae rough mutant R20/O1 ${ }^{-}$. Carbohydr Res 269, 1-7.

Tomás, J. M., Camprubí, S. \& Williams, P. (1988). Surface exposure of the $\mathrm{O}$-antigen in Klebsiella pneumoniae $\mathrm{O} 1: \mathrm{K} 1$ serotype strains. Microb Pathog 5, 141-147.

Tsai, C. M. \& Frasch, C. E. (1982). A sensitive silver stain for detecting lipopolysaccharides in polyacrylamide gels. Anal Biochem 119, 115-119.

Vinogradov, E. \& Perry, M. B. (2001). Structural analysis of the core region of the lipopolysaccharides from eight serotypes of Klebsiella pneumoniae. Carbohydr Res 335, 291-296.

Vinogradov, E., Frirdich, E., MacLean, L. L., Perry, M. B., Petersen, B. O., Duus, J. O. \& Whitfield, C. (2002). Structures of lipopolysaccharides from Klebsiella pneumoniae. Eluicidation of the structure of the linkage region between core and polysaccharide $\mathrm{O}$ chain and identification of the residues at the non-reducing termini of the $\mathrm{O}$ chains. J Biol Chem 277, 25070-25081.

Westphal, O. \& Jann, K. (1965). Bacterial lipopolysaccharide extraction with phenol-water and further application of the procedure. Methods Carbohydr Chem 5, 83-91.

Williams, P. \& Tomás, J. (1990). The pathogenicity of Klebsiella pneumoniae. Rev Med Microbiol 1, 196-204. 